\title{
$\varepsilon_{\beta}$
}

\section{Embryonic developmental study on inner ear of Columba livia domestica (the early, intermediate stages)}

\author{
El-Balshy Rm ${ }^{1 *}$, Abd El-Hady $\mathrm{Si}^{2}$, El-Hady M M ${ }^{2}$, El-Sayed $\mathrm{Sh}^{2}$ \\ ${ }^{1}$ Dept. of Zoology, Faculty of Science, Benha University, Egypt.Cell No.002-01000402435 \\ ${ }^{2}$ Dept. of Zoology, Faculty of Science, Benha University, Egypt \\ *Corresponding author E-mail: Drragaamustafa@gmail.com
}

\begin{abstract}
The present study deals with the embryonic development of the early and the intermediate embryonic stages of Columba livia domestica inner ear or the membranous labyrinth $(10,15,20,22,26,30,33,36$ and $47 \mathrm{~mm}$ total body length). During the early development (10 mm stage), neuroepithelium of the ventral rhompencephalon evaginates laterally to form an ectoderm thickening, the otic placode. The latter invaginates forming the otocyst that subsequently gives all other components of the membranous labyrinth. The surrounding mesenchyme is the origin of cartilaginous capsule of the ear. The endolymphatic duct is the first appeared structure in $15 \mathrm{~mm}$ stage, followed by cochlear duct (in $22 \mathrm{~mm}$ stage) and finally the three semicircular ducts. The latter begin in $26 \mathrm{~mm}$ stage and end in $47 \mathrm{~mm}$ stage .The inner ear contains sensory organs; the macula of ( utriclus, sacculus) and the crista ampullaris ( of the three semicircular canals ) and the basilar papillae of the cochlear duct; not only for the sense of hearing but also for the equilibrium ,stability and balance. The sensory organs of the intermediate stages (36 and $47 \mathrm{~mm}$ stages) showed no differentiation to hair or supporting cells. In the intermediate stage (47 mm stage), the inner ear has undergone a considerable development in its structure. It consists of a dorsal vestibular part including two connecting sacs (utriculus and the sacculus) and three semicircular canals and ventral cochlear part (the cochlear duct).
\end{abstract}

Keywords: Columba, Embryo, Early, Intermediate Stages, Inner Ear Development.

\section{Introduction}

A growing literature described many aspects of the avian auditory system, particularly at the level of the developing inner ear, responses of the auditory nerve, and avian auditory perception (e.g., Dooling \& Saunders, 1973; Rubel, 1978; Saunders et al., 1973 and Saunders \& Dooling, 1974). Then a proliferation of papers in the 1980 reported on many biological aspects of the avian middle and inner ears in (Manley, 1990 and Saunders \& Henry, 1988).

The otic vesicle of the chicken inner ear was investigated by (Cohen \& Fermin, 1978) and (Torres \& Giraldez, 1998). Emer-gence of hearing in the chicken embryo and auditory evoked responses in the cochlea and cochlear nuclei of the chick are tow problems have been revealed by (Saunders et al., 1973) and (Jones et al., 2006).

Lewis et al., (1985) and Torres \& Giraldez (1998), studied the sensory regions of chick and mouse inner ear and their innervations. They found that their inner ear is highly innervated by sensory neurons of the VIIIth cranial ganglia, and have two major cell types: hair-cells and supporting cells are considered as the basic unit of all sensory organs in the vertebrate inner ear.

Several studies dem $\neg$ onstrated that birds could regenerate their sensory hair cells (Cotanche, 1987; Cruz et al., 1987; Corwin et al., 1988 and Ryals \& Rubel, 1988). More importantly, other studies demonstrated that the regenerated sensory hair cells were functional (Smolders, 1999), and (Bermingham-Mc.Donogh and Rubel, 2003).

Comparative data on hearing-organ structure are available from the different vertebrates (Alsina et al., 2009). (Manley, 1990; Fay
\& Popper, 2002; Cantos et al., 2004; and kobayashi, 2008) worked on the inner ear chick, and reptiles.

Inner ear lineages are also of interest in the context of evolutionary homologies. For inner ear mechanosensory organs, the issue has been raised of whether they share an ancient evolutionary relationship to insect mechanosensory organs (Lewis, 1991; Fritzsch et al., 2000; Eddison et al., 2002). Both systems use Notch-Delta signaling during key stages of neuroblast delimitation (Eddison et al., 2002) and atonal homologs for cell fate specification (Bermingham et al., 1999; Chen et al., 2002 and Zheng \& Gao, 2000).

Other studies were done on the avian inner ear development (Bissonette \& Fekete, 1996; Satoh and Fekete, 2005; Fritzsch et al., 2006; Bell et al., 2008 and Alsina et al., 2009). The auditory sensory basilar papilla, and the vestibular macula lagena, which is thought to function in linear acceleration detection are reviewed in (Bissonnette \& Fekete, 1996). Another study on the development of sensory organs of the inner ear of birds and mouse applied by (Romanoff, 1960 and Von Bartheld et al., 1991). Another works were done to study the chick otic placode (Fritzsch, et al., 1997; Torres \& Giraldez, 1998 and Fekete, 1999). The main features of the peripheral auditory system of birds studied by (Dooling et al., 2000).

\section{Materials and methods}

The fertilized eggs of the Columba livia domestica are collected randomly from farms of Tukh, Qalubia, Egypt. After careful removing of the developmental embryo stages $(10,15,20,22,26$, $30,33,36$ and $47 \mathrm{~mm}$ total body length ) from the shells , they were 
fixed in an aqueous Bouin's solution for 24 hours, and then washed in $70 \%$ ethyl alcohol for several times to remove the excess of the fixative. The total body length of the embryo was measured from the tip of the beak to the cloacal opening. The head were stained with Borax carmine from 12 to 24 hours and then dehydrated , cleared, embedded in paraplast wax and serially sectioned transversally at ( 3- 5) $\mu \mathrm{m}$ thick and stained with Picrioindigocarmine stain . Photomicrographs of the serial sections were captured by the light microscope.

\section{Results}

\subsection{The early stages}

\subsection{1. $10 \mathrm{~mm}$ total body length}

This embryo represents the smallest obtained stage from the protoplasmic disc that floating on the yolk sac of the egg. In three brain vesicles; prosencephalon (fore brain), mesecephalon (mid brain) and rhombencephalon (Hind brain), (N.T.; HB. Fig.1).

The membranous labyrinth arises as a pair of ectoderm thickenings known as auditory or otic placodes on each side of head at the level the rhombencephalon, (O.PC. Fig.1). each placode appears as solid mass which increase in size due to cell prolifer-ation. The otic placode becomes invaginated forming fluid filled sac called auditory vesicle or otocyst (OT. Fig.1).

\subsection{2. $15 \mathrm{~mm}$ total body length}

In this stage, the inner ear has shown more differentiation than in the previous stage. The otocyst appears as an otic plate at the most anterior part of the auditory region (O.PL. Fig. 2). At the middle part, the otocyst ( OT., Fig.3) has an oval shape and a thin wall composed of pseudostratified columnar epithelium with an oval or round nuclei (PST.E., Fig. 4) .The otocyst is surrounded by periotic mesenchyme, mesenchyme of the auditory region (O. M.; OT. Fig.3). The dorsolateral portion of the middle part of the otocyst bulges out as a small protrusion, endolymphatic duct (EN.D, Fig.3) at the lateral wall facing the hind brain. At the same time, the otocyst is separated from the ectoderm and the developing rhombencephalon with interspersed otic mesenchyme.

\subsection{3. $20 \mathrm{~mm}$ total body length}

In this stage, the auditory vesicle is more enlarged and has comparatively wide cavity. At the anterior part, the wall of the vesicle is thick and will give the future labyrinth parts .The statoacoustic ( VIII th ) ganglion is clearly seen as a compact mass above the dorsal wall of the otocyst then gradually enters the brain (N.VIII., Fig. 5) . At the middle of the of the otocyst, the endolymphatic duct continues its growth (EN.D. PL.1 a 6).The otocyst is divided into a dorsal part that can be referred as the pars superior (PA.S. Fig. 6) and a ventral part that can be referred as the pars inferior (PA.I. Fig. 6).

\subsection{4. $22 \mathrm{~mm}$ total body length}

At the anterior and the middle parts of the otocyst, the cochlear duct begins to originate from the ventro-medial wall ( C.D., Fig.7) and the endolymphatic duct continues its growth as a sac, respectively ( EN.D., Fig.8) . The beginning of condensation process (the first step towards the capsule chondrogenesis) is indicated by presence of numerous nuclei in the surrounding mesenchyme around the wall of otic vesicle forming the con-densed mesenchyme (CO.M. Figs, 7\&8).

\subsection{5. $26 \mathrm{~mm}$ total body length}

In addition to the previous mentioned structures at the middle part of the otocyst , the lateral semicircular canal is first to be appeared at the lateral wall facing the ectoderm (L.SC.D., Fig.9). The coch- lear duct( C.D., Fig.9) is referred as the pars inferior and it will house both vestibular and auditory sensory organs. This pars inferior will give rise to( in the following stages) two sensory epithelia , the vestibular saccular macula and the auditory basilar papillae They are arranged along the medial wall from proximal to distal; saccular macula and the basilar papillae .

\subsubsection{0mm total body length}

In this stage, the inner ear enlarged in size more than previously and became surrounded by very complete condensed mesenchymal capsule except at the lateral side opposing to the brain or the distinct condensation of the mesenchyme is obvious but not around all parts, the outer lateral wall only (CO.CP. Fig.10).

The endolymhpatic duct and the lateral semicircular canal epithelium (EN.D, L.SC.D. Figs., 10\&11) continue their growth. At the posterior part of the otocyst, the cochlear duct here begins its twisting giving a slightly curved duct (C.D., Fig.11). The cochlear duct of columba is twisted rather than coiled.

\subsection{The intermediate stages}

\subsection{1. $33 \mathrm{~mm}$ total body length}

Every parts of the labyrinth are completely surrounded by a condensed precartilage forming capsule (O.CP.PC, Figs., 12\&13). At the anterior part of the otocyst the endolymphatic duct has extended dorsally forming the endolymphatic sac, (EN.S.Fig.12).

In this stage, the pars superior contains the utricle, a chamber which is continuous with the lateral semicircular epithelium lumen and the endolymphatic sac (UT., Fig.12). This pars is observed besides the pars inferior which appeared previously at the middle part of the otic vesicle, the pars inferior separates into the saccule and the twisted cochlear duct respectively( S., C.D., Fig.12), the communication between the two compartments constricted and narrowed, so that both are interconnected by ductus reuniens ( $R$. D., Fig.12) . At the posterior part of the otic vesicle, the semicircular ducts begin its separation from the utricle; the anterior and the posterior semicircular ducts. This process is initiated from paired out pocketing of the otic epithelium .In the central region of the wall of this outpoketing, the two become thinner ( thin epithelium), then detach from the underlying mesenchyme and approaching each other to form the fusion plates, the anterior and the posterior fusion plates (A.F.PL., P.F.PL., TH.E., RE.M., Fig.13) . The epithelial cells that meeting at the fusion plates are melted into a single layer and subsequently disappear via a programmed cell death mechanism and the mesenchymal cells have replaced the epithelium (RE.M, Fig.13).

\subsection{2. $36 \mathrm{~mm}$ total body length}

Most elements forming the otic region show further development. In the present stage, the otic capsule converted to a permanent precartilage (O.CP.PC., Fig.14) and the capsule still found on the lateral side of the hind brain and not connected to the basal plate (O.CP.PC., B.PL., Fig.14) .The cochleovestibular nerve of this stage is branched into two rami, the cochlear branch for the cochlear duct innervations and the vestibular branch for the innervations of pars superior or the vestibule (C.NV. V.NV. Figs., 15\&16). The cochlear duct continues its growth ( C.D., Figs., 14,15\&18) and it is innervated by the cochlear branch of the cochleovestibular nerve ( C.NV., Fig.15) ) The pars superior contains the utricle (UT., Figs.,16,17,18\&19), a chamber which is continuous with the lateral semicircular epithelium lumen and the endolymphatic sac and it is innervated by the vestibular branch of the cochleovestibular nerve ( V.NV., Fig.16) At the posterior part, the process of separation of the semicircular ducts is continued as previously, the anterior and the posterior ducts are formed. In this stage, the lateral fusion plate is formed leading to separation of the lateral semicircular duct (L.F.PL., L.SC.D. Fig.17). the first differentiation of a sensory organ occurs in this stage. The columba posterior crista of the posterior semicircular duct is the first duct to 
be appeared (P.CR, P.SC.D, Fig.17). Also, the endolymphatic sac has been shifted to the posterior part and continues its growth at this level (EN.SC, Figs., 18\&19).

\subsection{3 $.47 \mathrm{~mm}$ total body length}

This is the oldest stage of the collection in this work where the structures of the otic region show extensive development. The otic vesicle of columba is surrounded by a complete capsule of true cartilage (TR.C. Figs., 20\&33). The otic capsule differenti-ated to relatively permanent cartilage, but there is also areas of temporary precartilage surrounding the epithelial ducts that permit the enlargement of the future cartilaginous canals called the reticular zone (TR.C. TM.C. RT.Z. Fig.33). the cartilaginous capsule in this stage revealed that there are fife outer em-bossments of the auditory capsule. These are prominentia coch-learis, prominentia semicircularis lateralis, prominentia semi-circularis anterior, prominentia semicircularis posterior and prominentia utriculus ( PR.COCH., PR.SC.L., PR.SC.A., PR.SC.P., PR UT., Figs.,20,21,23,25,27,28,34\&35).The lateral wall of the prominentiae cochlearis has two foramens, the fenesta ovalis and the foramen perilymphaticum (F.OV. FO. PER., Figs., 21\&22). The lateral wall of the cochlear part of the inner ear is subjected to reabsorption process in the pre-existing cartilage to form the fenestra ovalis .This represent a hole in which fits the stapes of the columella auris of the middle ear. When the stapes abuts against the lateral wall of cochlear part, and by continuous depression of the stapes on this wall, this leads to the degeneration of the preexisting cartilage and finally forms the fenesrta ovalis. The other foramen is existed in the ventro-lateral wall of the cochlear part. This is the foramen perilymphaticum that is considered as the posterior fenestra ovalis .The latter is situated over the foramen perilymphaticum. Between the two fenestrae, the promontrium is located as a cartilaginous bridge between them (PROM., Figs., $21 \& 22)$.The mitotic cartilage in the present stage undergoes considerable growth, where it extends medially and laterally to form a floor under the canalicular part of the auditory cartilaginous capsule (P.MET.C.V. P.MET.C.D, MET.C. Fig. 21).)

The fissure metotica of the present stage changes its shape due to the fusion of the two portions of the metotic cartilage .This fissure splits into three parts; the anterior, posterior and foramen jugular. The first foramen is called the aperture medialis recesses scalae tympani (A.M.RE. ST., Fig. 21).). Through this foramen, the glossopharyngeal nerve passes out the cranium and it leads to recesses scalae tympani .The second foramen is the fissure exoccipito capsularis (F. EX., Figs., 23, 24,25,26,27 \&29). It separates the dorso-lateral side of the occipital arch and

The ventro-medial edge of the canalicular portion. The third foramen is the jugular foramen, and it encloses the vagus -accessory nerve (FOR.NX. \& XI. Fig. 21).

The tympanic cavity of middle ear represents the space between dorso-lateral wall of the prominentae cochlearis of the inner ear and the processes opticus of the quadrate cartilage of the hyoid arch. The tympanic cavity is bordered latero-ventrally by the external auditory meatus (T.CAV, P.OT. PR. COCH., EX. A.M., Fig. 20). The three semicircular ducts( anterior , posterior and lateral) of the membranous labyrinth are fully formed( A. SC.D., L.SC.D., P.SC.D., Figs.,24,27,28,29,30,34\&35) .The membranous labyrinth of this stage has taken a new developed fashion. It is divided to dorsal vestibular part ( the vestibule) that contain vestibular organs and ventral cochlear part that contain the auditory organ (cochlear duct) that is responsible for auditory function ( sense of hearing or audition) . The cochlear duct of Columba is twisted tube rather than coiled as in higher verte-brates. Also tissue specification leads to formation of the teg-mentum vasculosum, a tissue that is responsible for the endo-lymphatic ionic composition and endocochlear potential (C.D., TEG.V. Figs.,27\&28). The vestibular components consisted of two connecting sacs or the otolith organs ( the utricle , the sac-cule ) and three semicircular canals (UT., S., L.SC.D., A.SC.D., P. SC.D., Figs., 26,27,28,29,30\&31). These three canals are oriented in the three dimensions of space (one horizontal, one anterior vertical and one posterior vertical).There are fife sensory organs formed in this stage. They are the utriculus macula, the sacculus macula and the three crista of the three semicircular ca-nals (anterior crista, lateral crista and posterior crista) at the en-trance of each canal (A.CR, L.CR. P.CR, Figs., 28, 31\&32). The macula, the sensory epithelial thickening in the utricle, the utriculus macula and saccule, the sacculus macula (UT.M, S.M., Figs., 28\&29). They are associated with otilithic membrane (a dense crystals attached ciliary bundles of the hair cells. They facilate the vestibular and auditory functions by transmitting ac-celeration forces and sound vibrations, respectively (Kelly, 1991).The crista, the sensory epithelium occurs at the entrance of the complete canal; anterior, posterior and lateral crista (A.CR, P.CR. L.CR. Figs., 28, 31\&32). It lacks otiliths but has a gelatinous cupula , a special structure above the crista that is sensitive to the fluid motion (the endolymh of the ducts ) caused by the angular acceleration so it detect the angular acceleration of the head in the three directions ( CUP., Fig.32 ).

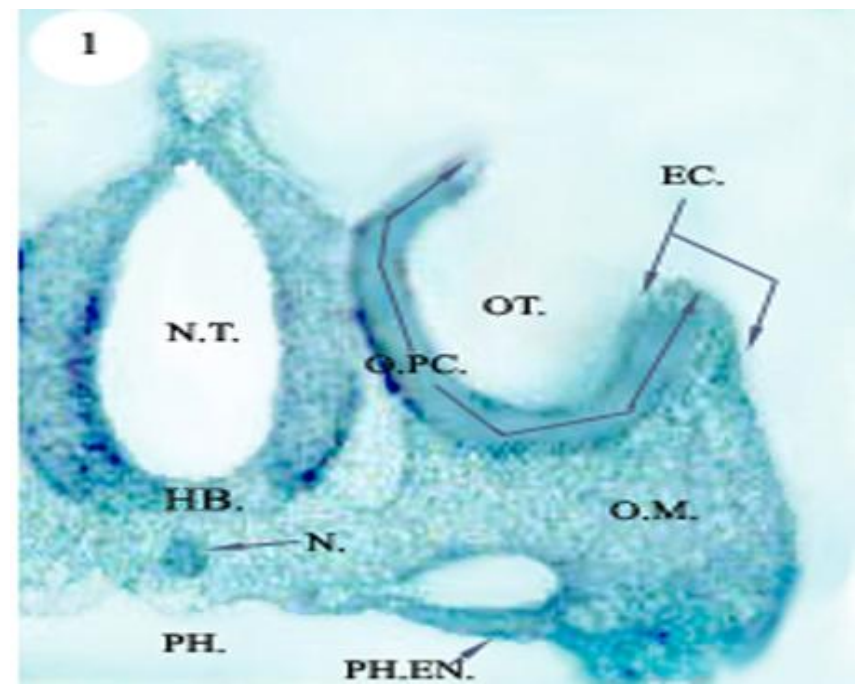

Fig. 1: Photomicrograph of A Transverse Section in the Auditory Region of Columba Livia, $10 \mathrm{Mm}$ Stage Showing the Otic Placode (O.PC.) invagination forming the Otocyst (OT.) X 100.

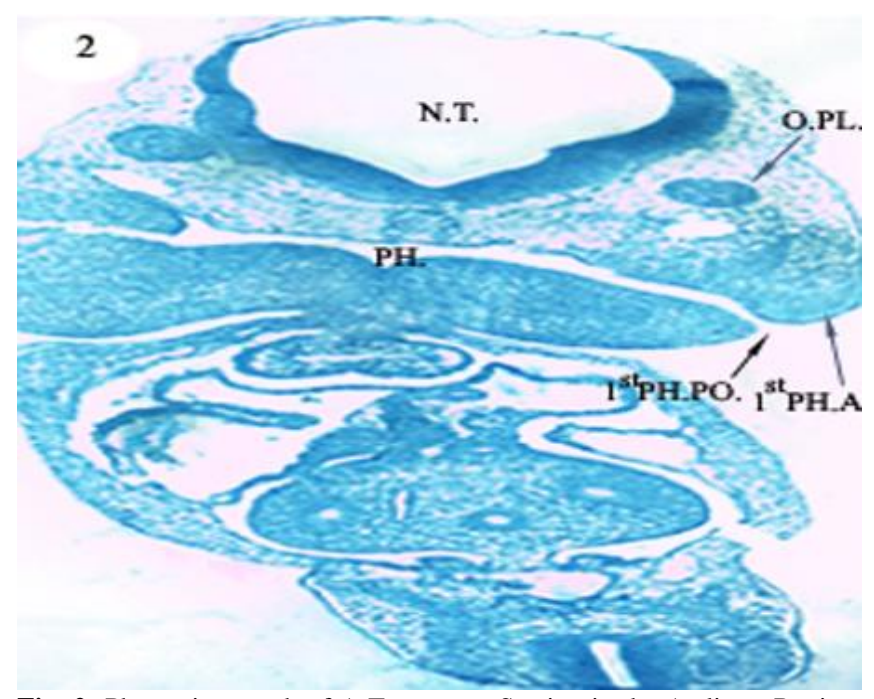

Fig. 2: Photomicrograph of A Transverse Section in the Auditory Region of Columba Livia, $15 \mathrm{Mm}$ Stage (the Anterior Part of Auditory Region) Showing the Otic Plate (O.PL.) X 40. 


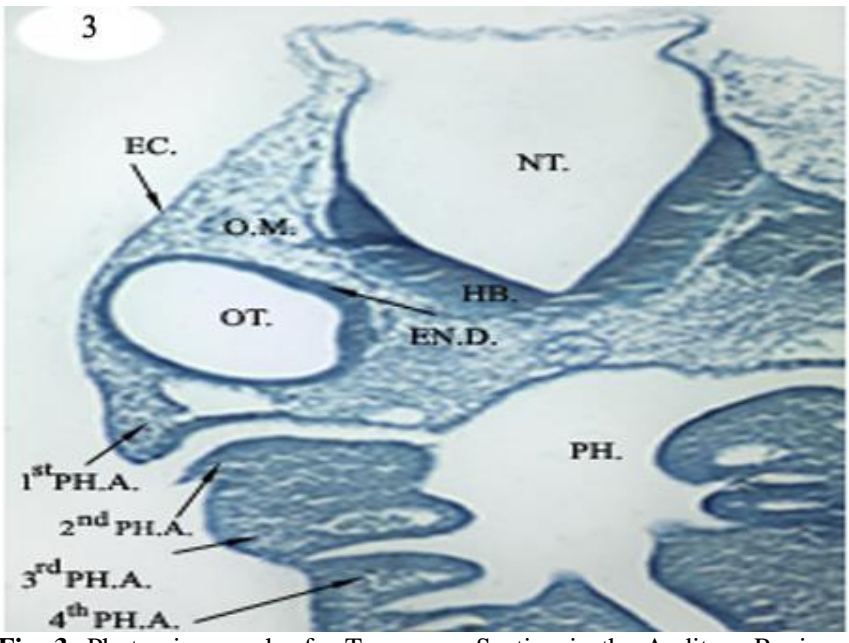

Fig. 3: Photomicrograph of a Transverse Section in the Auditory Region of Columba Livia, $15 \mathrm{Mm}$ Stage (the Middle Part of the Auditory Region) Showing The Complete Closure of the Otic Placode Forming the Otocyst Or the Otic Vesicle (OT.) and its Surrounding Otic Mesenchyme (O.M.) $\mathrm{X} 40$.

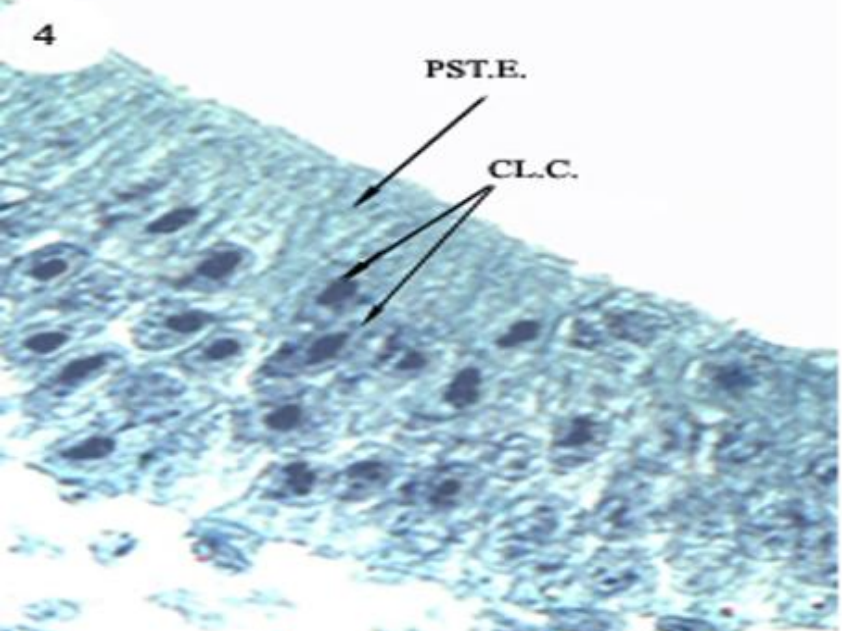

Fig. 4: Photomicrograph a of Transverse Section in the Auditory Region of Columba Livia, $15 \mathrm{Mm}$ Stage a Higher Magnification of a Part of the Otocyst Wall in A3 and Its Psedostratified Epithelium That Is Formed of Columnar Cells (PST.E. CL.C.) X600.

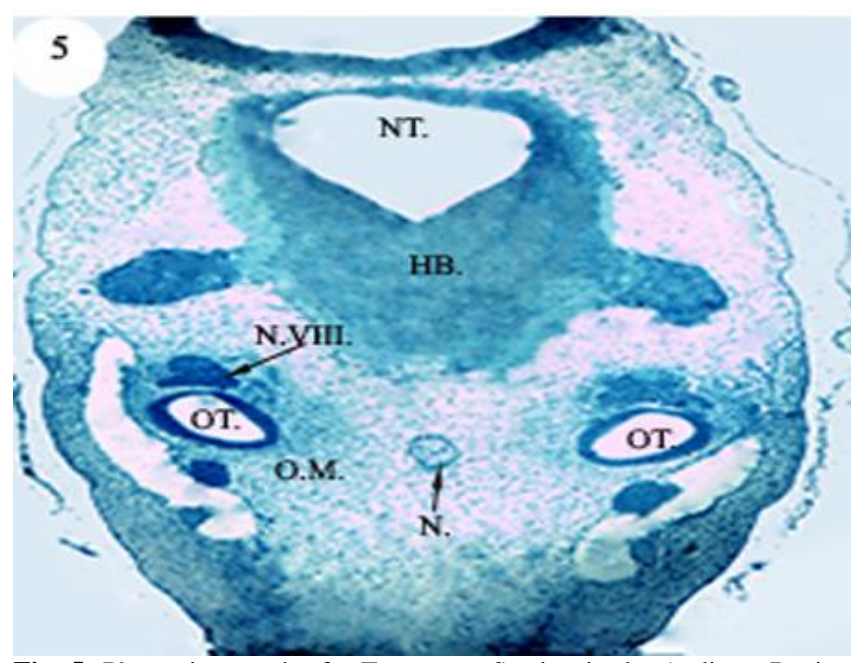

Fig. 5: Photomicrograph of a Transverse Section in the Auditory Region of Columba Livia, $20 \mathrm{Mm}$ Stage (the Anterior Part) Showing the Otocyst and the Cochleo- Vestibular Ganglion ( OT. , N.VIII ) X40.

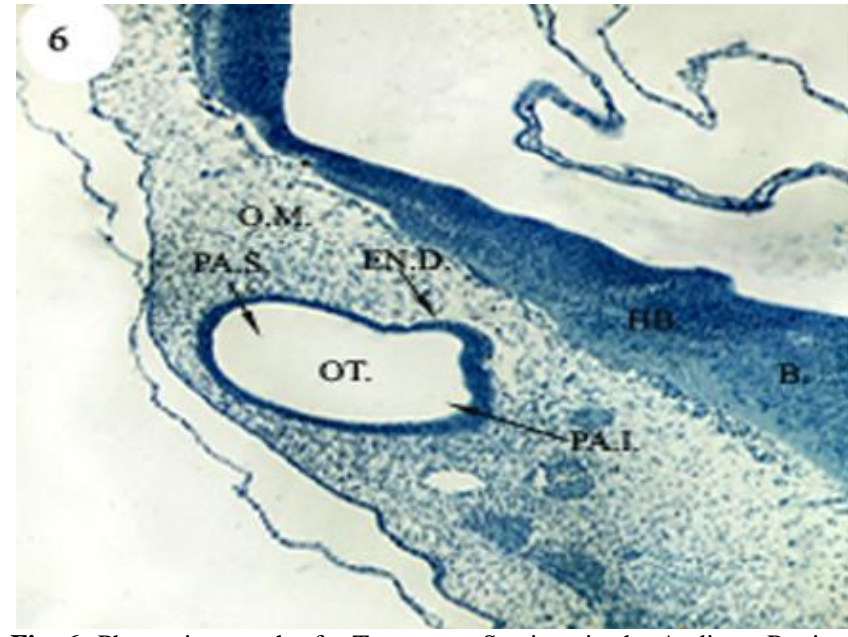

Fig. 6: Photomicrograph of a Transverse Sections in the Auditory Region of Columba Livia, $20 \mathrm{Mm}$ Stage, the Middle Part Showing the Endolymphatic Duct ( EN.D.), the Surrounding Otic Mesenchyme (O.M.) ,the Parsinferior (PA.I.) and the Pars Superior (PA.S.) X40.

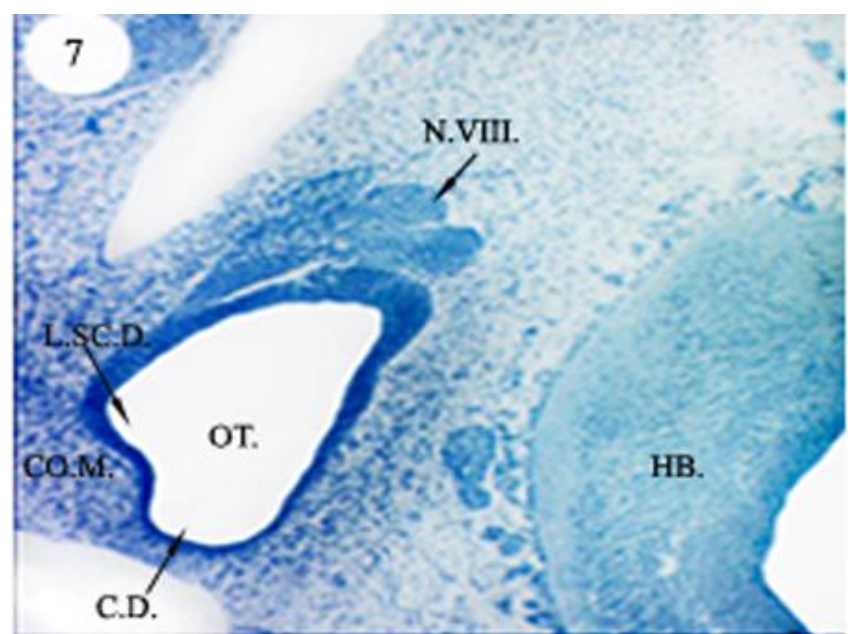

Fig. 7: Photomicrograph a of Transverse Section in the in the Auditory Region of Columba Livia, 22mm Stage, (the Anterior Part) Showing the Lateral Semicircular Duct (L, SC.D), the Cochlear Duct (C.D) and the Condensed Otic Mesenchyme (CO.M) X100.

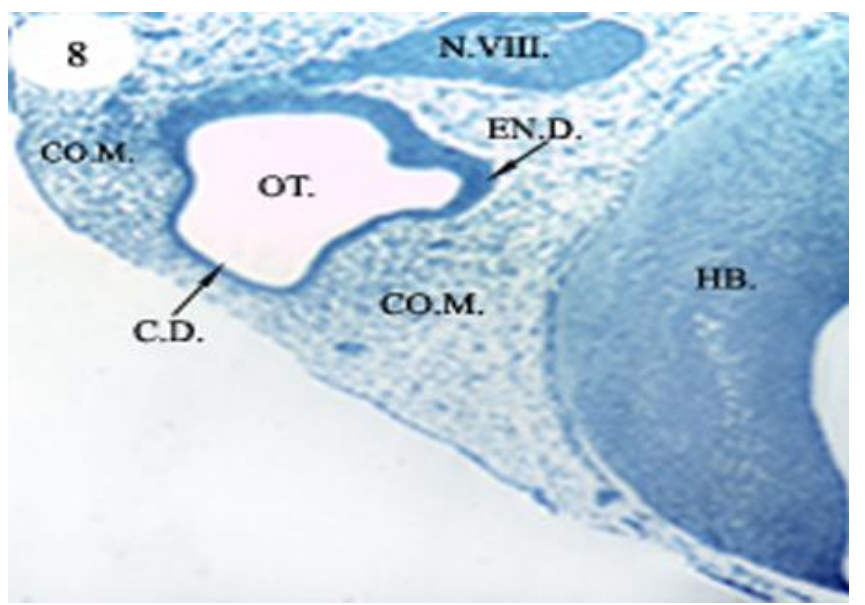

Fig. 8: Photomicrograph of a Transverse Section in the Auditory Region of Columba Livia, $22 \mathrm{Mm}$ Stage (the Middle Part) Showing the Endolymphatic Duct (EN.D.) and the Condensed Mesenchyme (CO.M.) $\mathrm{X} 100$. 


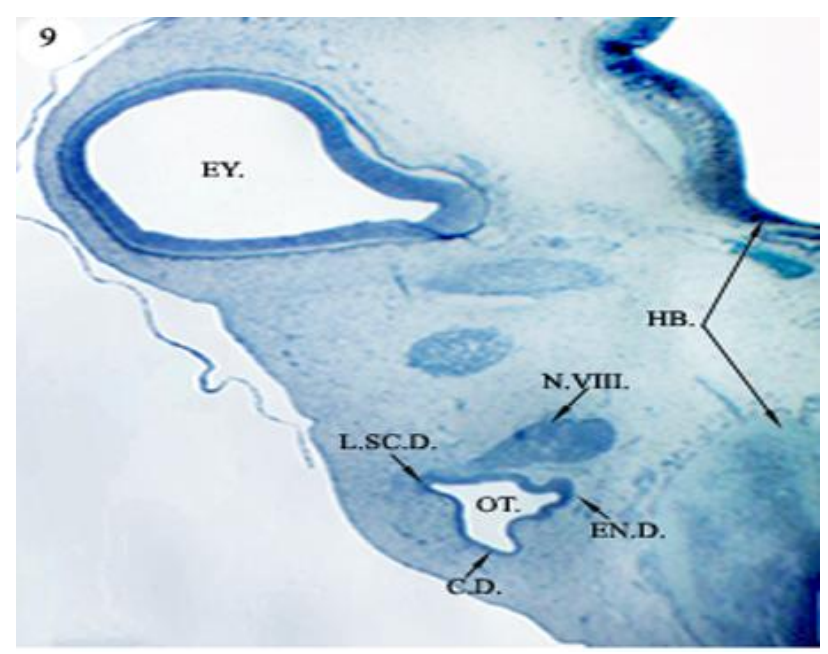

Fig. 9: Photomicrograph of a Transverse Section in the Auditory Region of Columba Livia, $26 \mathrm{Mm}$ Stage (the Middle Part) Showing Enlargement of the Lateral Semicircular Duct (L.SC.D.), Endolymphatic Duct (EN.D.) and the Cochlear Duct (C.D.) X40.

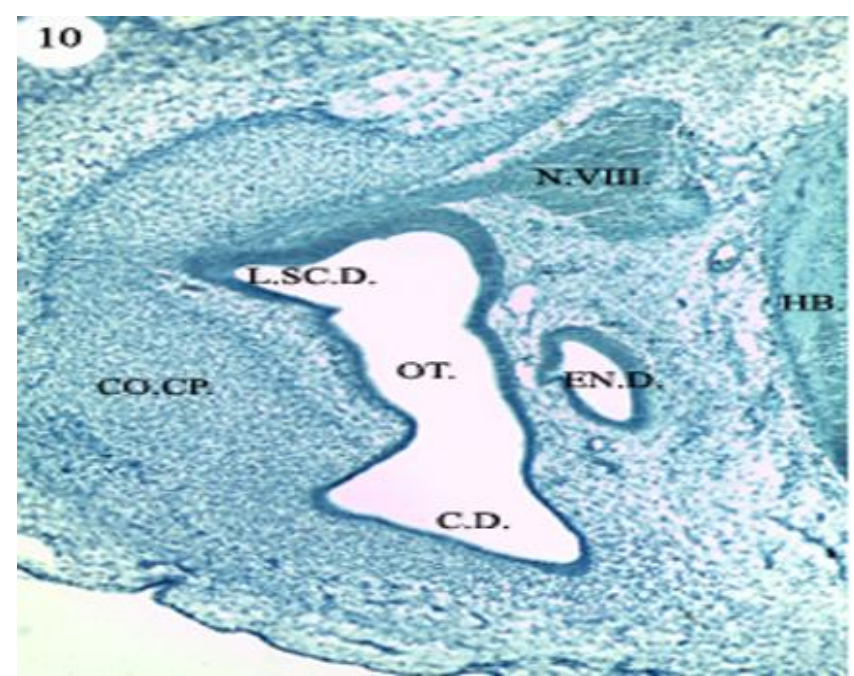

Fig. 10: Photomicrograph of a Transverse Section in the Auditory Region of Columba Livia,30 Mm Stage (the Middle Part )Showing the Endolymphatic Duct ( EN.D.), Lateral Semicircular Duct ( L.SC.D.) ,the Cochlear Duct (C.D.) , the Complete Condensed Mesenchymal Capsule ( CO.CP.)And the Cochlea-Vestibular Nerve (N.VII) X100.

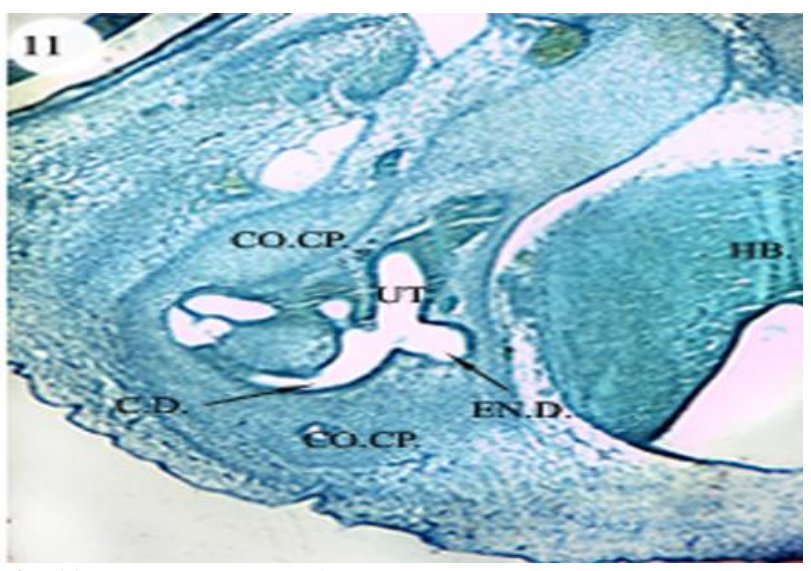

Fig. 11: Photomicrograph of a Transverse Section in the Auditory Region of Columba Livia, $30 \mathrm{Mm}$ Stage (the Posterior Part) Showing the Twisted Cochlear Duct (C.D.) and the Beginning of the Utriculus (UT.) X100.

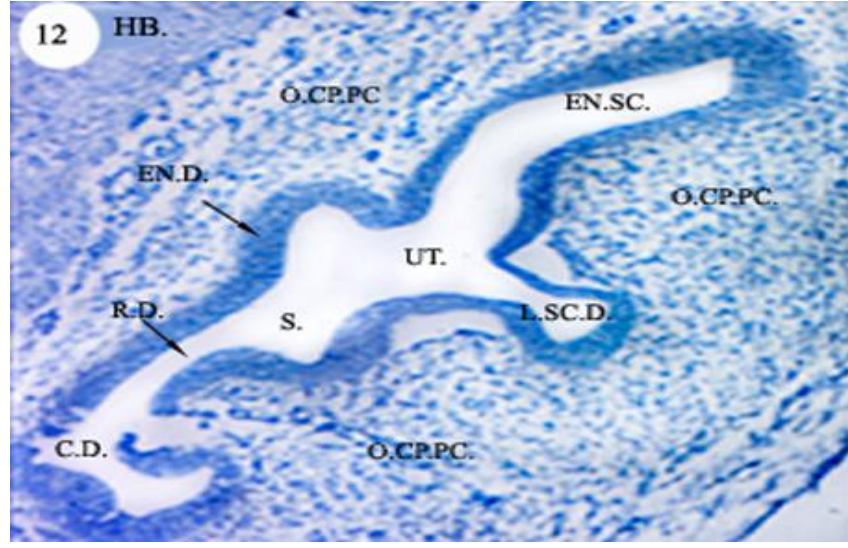

Fig. 12: Photomicrograph of a Transverse Section in the Auditory Region of Columba Livia, $33 \mathrm{Mm}$ Stage (the Anterior Part) Showing the Otic Capsule Precartilage (O.CP.PC.) and the Endo-Lymphatic Sac( EN.SC.), Latral Semicircular Duct ( L.SC.D.) ,Utriculus( UT.), Sacculus ( S.) and Cochlear Duct (C.D.) X 200.

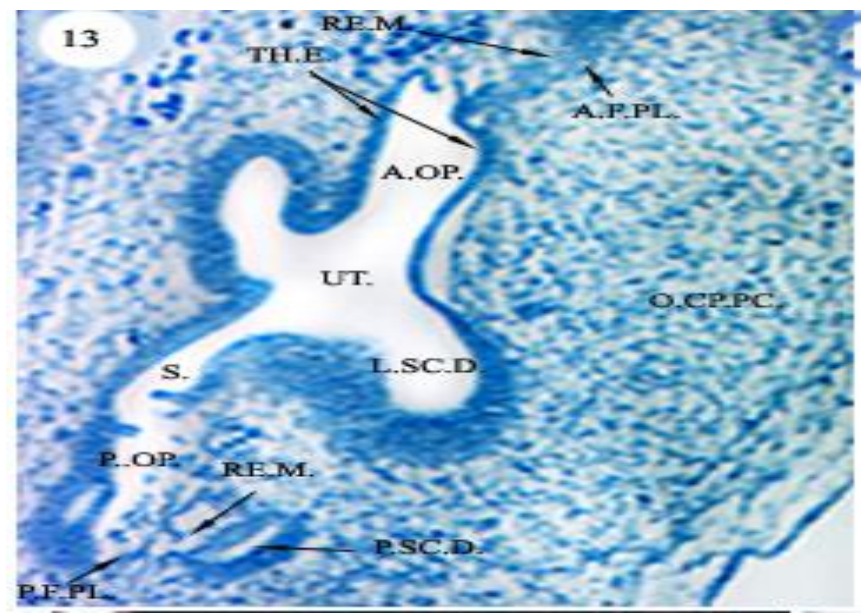

Fig. 13: Photomicrograph of a Transverse Section in the Auditory Region of Columba Livia, $33 \mathrm{Mm}$ Stage (the Posterior Part) Showing the Anterior and Posterior Outpocketings (A.OP. \& P.OP.) And Their Fusion Plates (A.F.PL. \& P.F.PL.), the Replacing Mesenchyme (RE.M.) and the Surrounding Capsule Precartilage (O.CP.PC.) X 200.

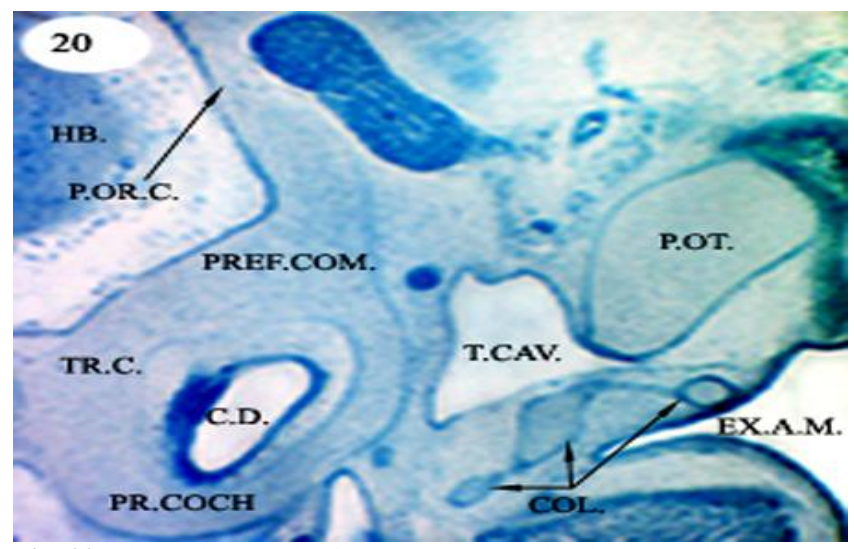

Fig. 20: Photomicrograph of a Transverse Section in the Auditory Region of Columba Livia, $47 \mathrm{Mm}$ Stage (the Most Anterior Part) Showing the True Cartilaginous Capsule( TR.C.) ,the Cochlear Duct (C.D.), Prefacial Commissure (PREF.COM.) and the Position of Middle Ear Elements (Columella, COL.; Tympanic Cavity, T.CAV. and External Auditory Mateus, EX.A.M.) In Relation to the Inner Ear X 40. 


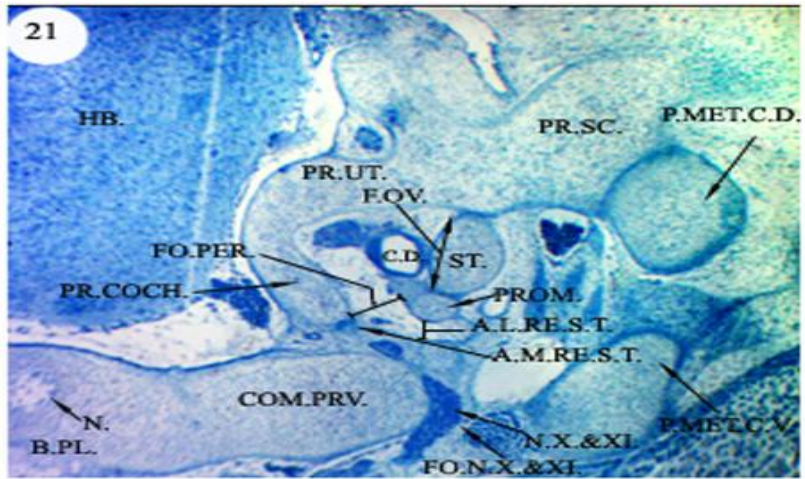

Fig. 21: Photomicrograph of a Transverse Section in the Auditory Region of Columba Livia, $47 \mathrm{Mm}$ Stage (the Anterior Part) Showing the Beginning of the Prominent (Utriculus, PR.UT. \& Semicircularis, PR.SC.), Fenestra Ovalis (F.OV.) of the Middle Ear Stapes (ST.) Is Opening Into the Inner Ear, Promontorium (PROM.), the Commissural Praevagalis(COM.PRV.) and The Position of Auditory Capsule In Relation to the Basal Plate (B.PL.) X 40.

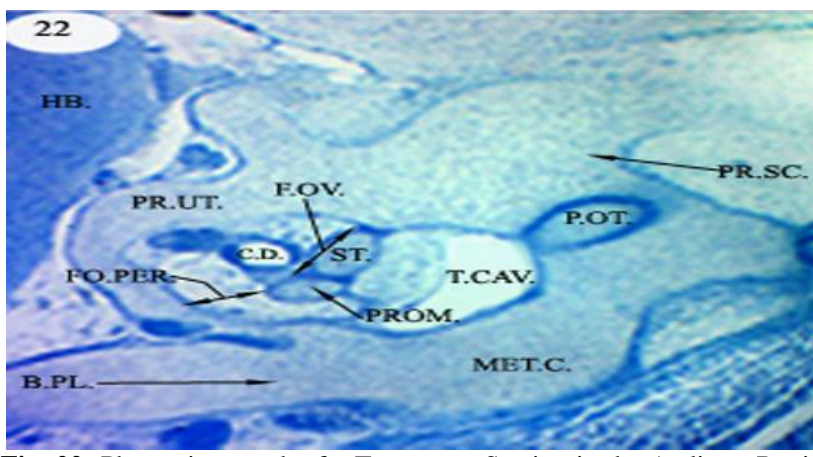

Fig. 22: Photomicrograph of a Transverse Section in the Auditory Region of Columba Livia, $47 \mathrm{Mm}$ Stage (the Middle Part) Showing the Enlargement of the Prominentia (Utriculus, UT. \& Semicircu-Laris, PR.SC.) and the Ending of the (Tympanic Cavity, T.CAV. \& Stapes,ST. ).Of the Middle Ear And Ending of the Processus Oticus (P.OT.) of the Quadrate Cartilage $\mathrm{X} 40$.

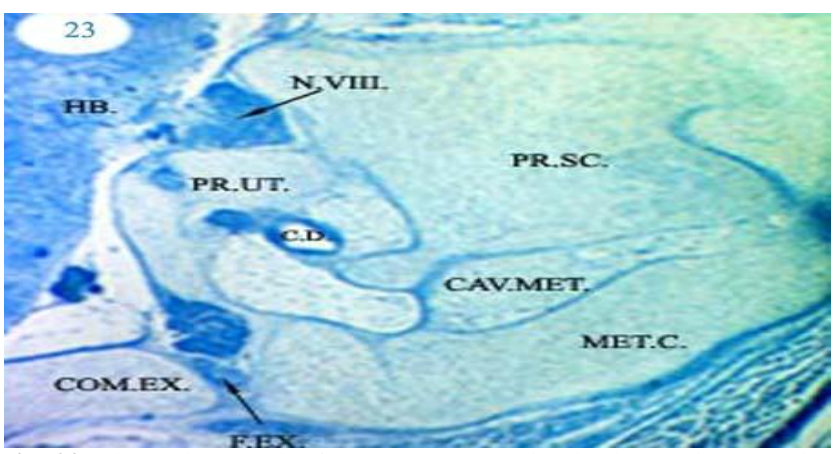

Fig. 23: Photomicrograph of a Transverse Section in the Auditory Region of Columba Livia, $47 \mathrm{Mm}$ Stage (the Middle Part) Showing the Enlargement of the Prominentia (Utriculus, UT. \& and Semicircularis, PR.SC.), Fusion of the Two Parts of the Metotic Cartilage (MET.C.) Forming the Floor of the Auditory Capsule, the Cavum Metoticum (CAV.MET.) and the Appearance of the Commissural Exoccipitocasularis (COM.EX.)X 40.

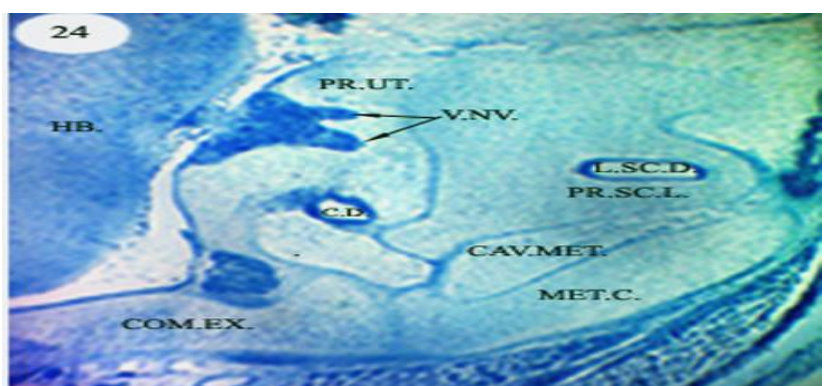

Fig. 25: Photomicrograph of a Transverse Section in the Auditory Region of Columba Livia, $47 \mathrm{Mm}$ Stage (the Posterior Part) Showing the Closure of the Prominentia Utriculus (UT.) After Entrance of the Vestibular Branch of the Cocleo Vestibular Nerve (V.NV.) X40.

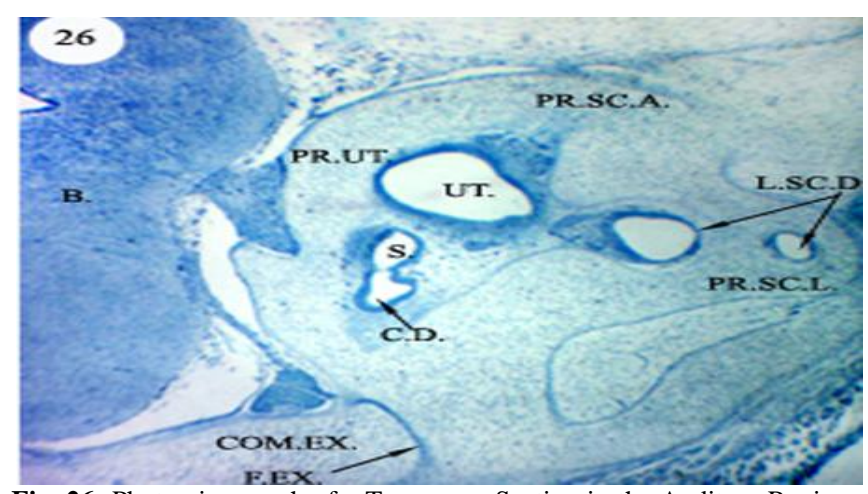

Fig. 26: Photomicrograph of a Transverse Section in the Auditory Region of Columba Livia, $47 \mathrm{Mm}$ Stage (the Posterior Part) Showing the Commissural Exoccipitocasularis (COM.EX.) and Its Fissure (F.EX.), Utriculus (UT.), Sacculus (S.), Prominentia Semicicu-Laris Lateralis (PR.SC.L.) and it's Duct (L.SC.D.), Prominent Semicicularis Anterior (PR.SC.A.) X40

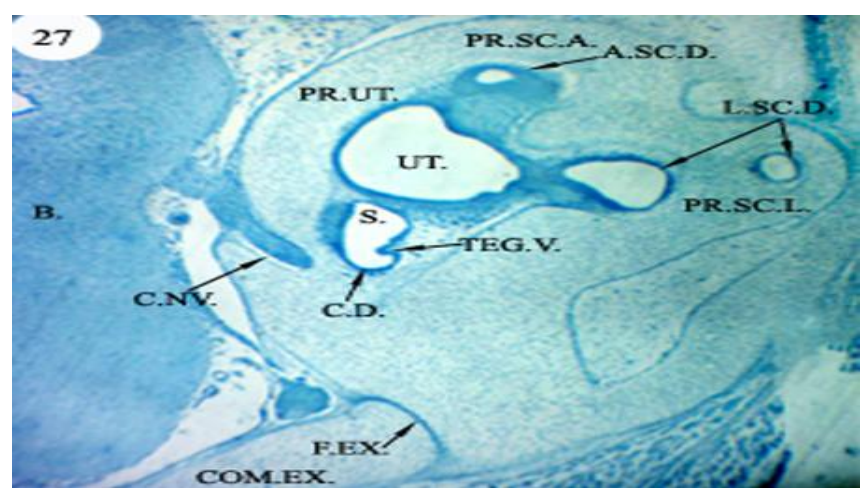

Fig. 27: Photomicrograph of a Transverse Section in the Auditory Region of Columba Livia, $47 \mathrm{Mm}$ Stage (the Posterior Part) Showing Appearance of the Anterior Semicircular Duct (A.SC.D.), Cochlear Duct (C.D.) and its Tegmentum Vaculosum (TEG.V.) and the Coclear Branch (C.NV.) of Cochleo Vestibular Nerve Passing Through the Prominentia Triculus (UT.) X40.

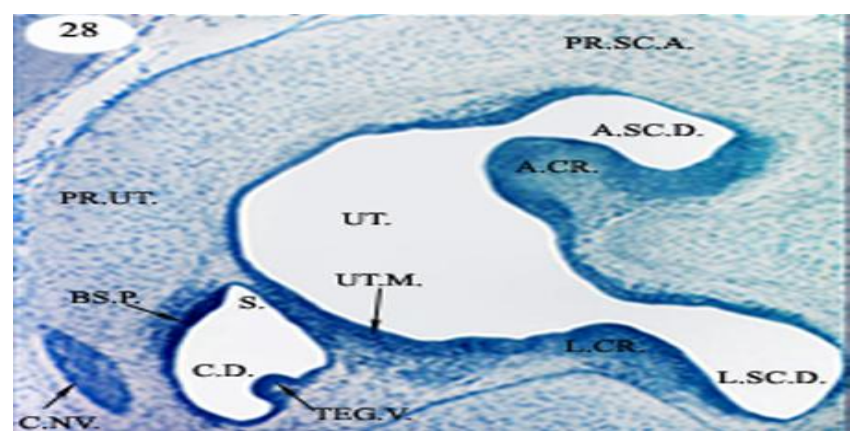

Fig. 28: Photomicrograph of a Transverse Section in the Auditory Region of Columba Livia, $47 \mathrm{Mm}$ Stage (the Posterior Part) Showing the Complete Passage of the Cochlear Branch (C.NV.) of Cochleovestibular Nerve Through the Prominentia Utriculus, Appearance of the Anterior and Lateral Crista (A.CR. \& L.CR), Utriculus Macula (UT.M.) and Thtbasilar Papilla( BS.P.) of the Cochlear Duct (C.D.) X100.

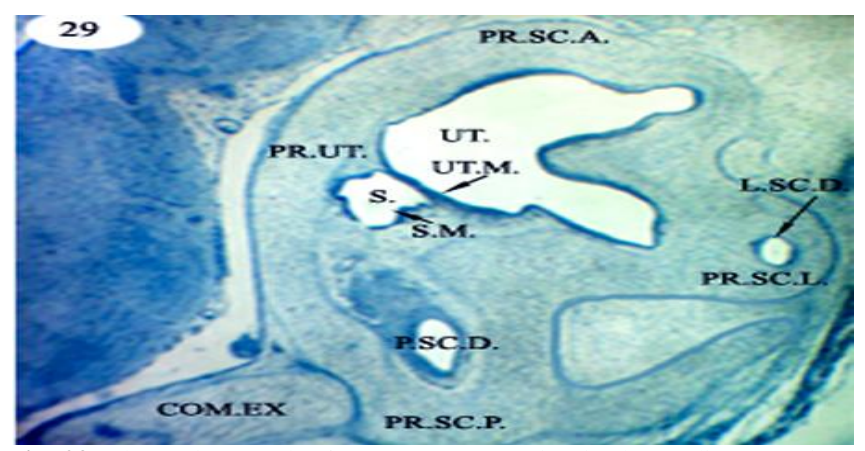

Fig. 29: Photomicrograph of a Transverse Section in the Auditory Region of Columba Livia, $47 \mathrm{Mm}$ Stage (the Posterior Part) Showing the Appearance of the Saccular Macula (S.M.), Prominentia Semicicularis Posterior (PR.SC.P.) and the Posterior Semicircular Duct (P.SC.D.) X40. 


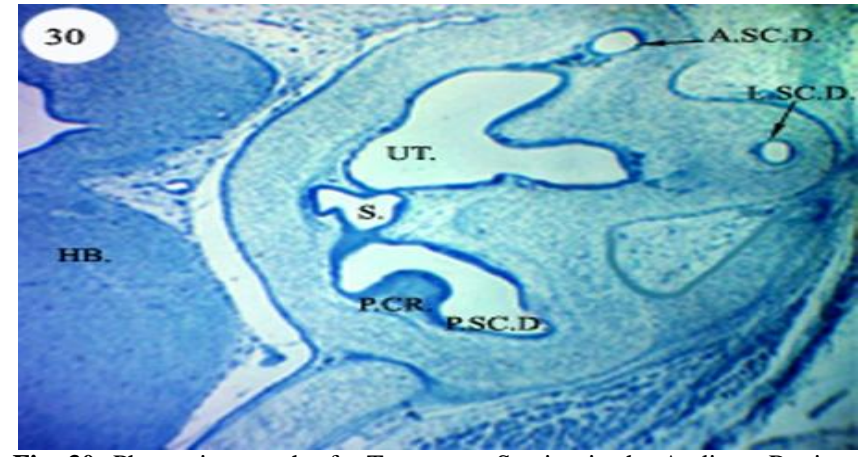

Fig. 30: Photomicrograph of a Transverse Section in the Auditory Region of Columba Livia, $47 \mathrm{Mm}$ Stage (the Posterior Part) Showing Appearance of the Posterior Crista (P.CR.) of the Posterior Semicircular Duct (P.SC.D.) X40.

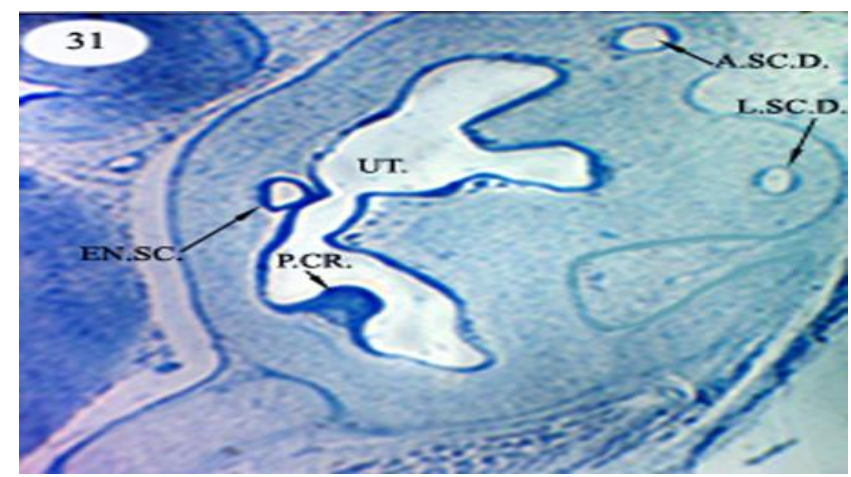

Fig. 31: Photomicrograph of a Transverse Section in the Auditory Region of Columba Livia, $47 \mathrm{Mm}$ Stage (the Posterior Part) Showing the Appearance of the Endolymphatic Sac (EN.SC.) on the Lateral Side Facing the Brain X40.

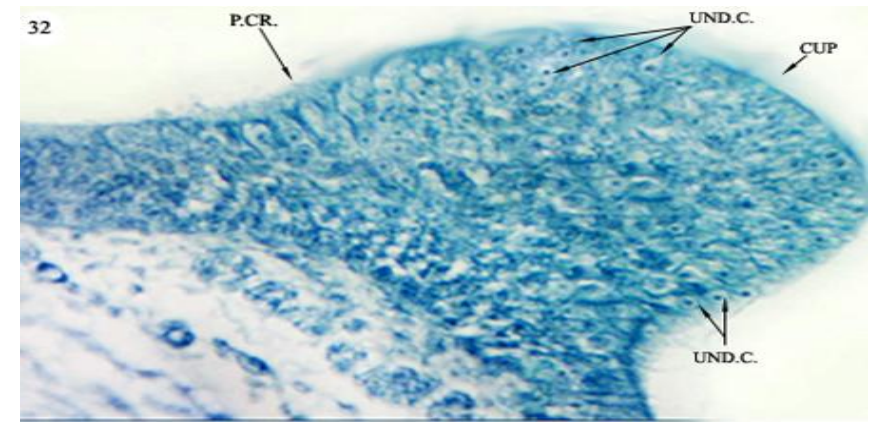

Fig. 32: Photomicrograph of a Transverse Section in the Auditory Region of Columba Livia, $47 \mathrm{Mm}$ Stage(the Posterior Part) Showing a Higher Magnification of the Posterior Crista ( P.CR.), the Undifferentiating Hair Cells( UND.C.) and the Cupula of the Crista (CUP.) X400.

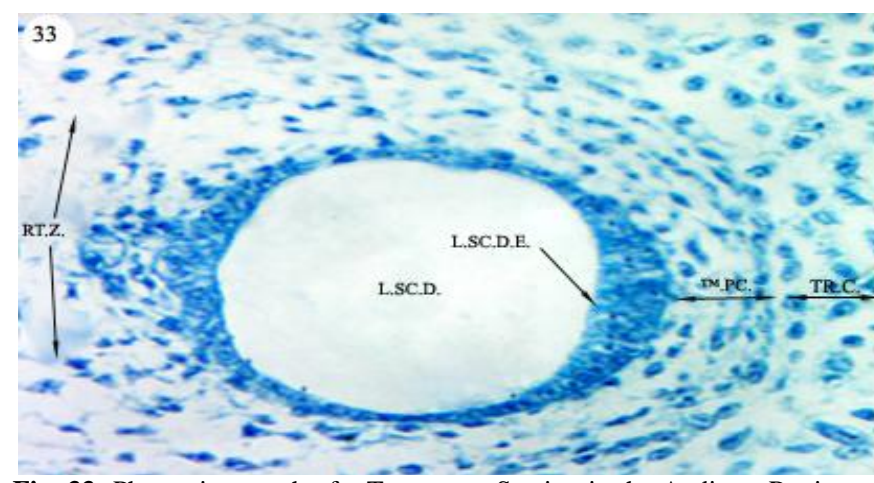

Fig. 33: Photomicrograph of a Transverse Section in the Auditory Region of Columba Livia, $47 \mathrm{Mm}$ Stage (the Posterior Part) Showing a Higher Magnification of the Lateral Semicircular Duct ( L.SC.D.), the Temporary Precartilage (TM.PC.) Surrounding the Duct, the True Cartilaginous Capsule (TR.C.) and the Reticular Zone of the Duct (RT.Z.) X400.

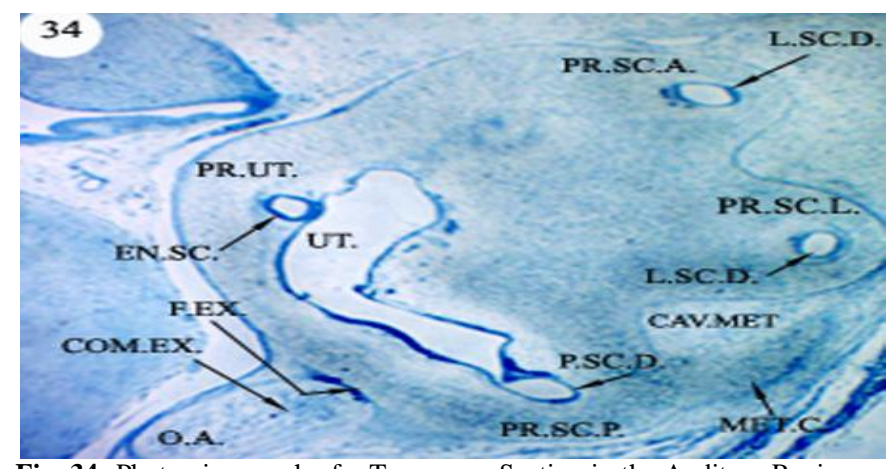

Fig. 34: Photomicrograph of a Transverse Section in the Auditory Region of Columba Livia,47 Mm Stage(the Most Posterior Part )Showing the Occipital Arch ( O.A.), the Three Semicircular Ducts ( A.SC.D., L.SC.D. \&P.SC.D.) and the Endolymphatic Sac (EN.SC.) X40.

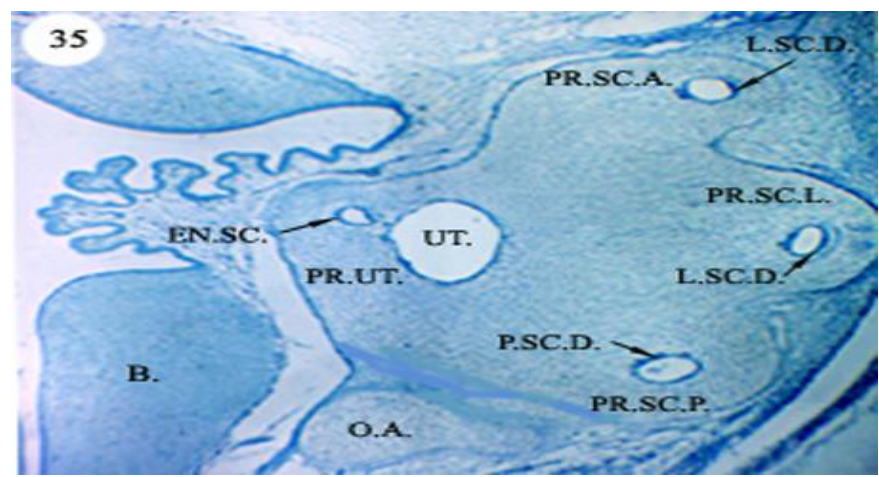

Fig. 35: Photomicrograph of a Transverse Section in the Auditory Region of Columba Livia,47 Mm Stage, the Most Posterior Part Showing the Occipital Arch( O.A.), the Three Semicircular Ducts ( A.SC.D., L.SC.D. \& P.SC.D.), the Endolymphatic Sac (EN.SC.) and the Ending of the Utriculus (UT.) X40.

\section{Discussion}

The description of the early and intermediate embryonic developmental stages of the inner ear of the columba livia domestica has revealed that it is more or less in conformity with the general plan of other birds.

In the present study, the columba ear morphogenesis receives contribution from the three germ layers, the ectoderm, the endoderm and the mesoderm .In $10 \mathrm{~mm}$ embryo stage, the ectoderm is the source layer for membranous labyrinth of the inner ear .It initiates the otic placode which in turn give rise to the other components of the membranous labyrinth. The cartilaginous auditory capsule that is differentiated from the mesenchyme of the otic area so it is mesoderm in origin. These results agreed with Dallos, (1988); Donaldson et al. (1992) and Rubel, (1992) in their studies on human.

(Bissonnette \& Fekete, 1996); (Fritzsch et al., 1997) and (Schlosser, 2010) explained that the overall pattern of the development of the inner ear is similar among the vertebrates. Development of the vertebrate inner ear begins with thickening of the surface of the ectoderm adjacent to the rhombosphere that is called otic placode. The latter invaginates and closes to form the otic vesicle or otocyst followed by remarkable morphometric changes ; cell differentiation and chondrogenesis process, as a result, formation of the complete three- directioned labyrinth containing sensory organs for balance and hearing is developed .They explained that in most vertebrates, including the chick, the complex process of inner ear formation begins with the specification of an epithelial placode that thickens and invaginates to form an otic cup. As the development proceeds, the otic cup closes to form the otic vesicle. The otic epithelium undergoes a series of poorly understood cellular movements to form the complex three-dimensional structure of the mature avian inner ear. The posterior semicircular canal and the superior semicircular canal develop from the superior dorsal region of the otocyst while the lateral semicircular canal is derived 
from the more ventral region. The endolymphatic duct and sac emerge from the dorsomedial region of the otocyst. The cochlear duct elongates from the ventromedial region.

In the present study, the inner ear firstly appear as ectoderm thickening, the otic placode, in $10 \mathrm{~mm}$ total body length then followed by the otocyst that is clearly seen at $15 \mathrm{~mm}$ total body length . This otocyst is a vesicle of columnar cells on both sides of the hind brain and formed by the placode invagination. This description is confirmed by (Baker \& Bronner-Fraser, 2001 and Schlosser, 2010) .They revealed that the entire inner ear and its associated sensory ganglia derive from the otic placode.

Knowlton, (1967) explained that in birds and mammals, the placode invaginates forming a cup and finally pinches off the surface ectoderm as a hollow vesicle of internalized epithelium. Haddon and Lewis, (1996) .They found that the tetrapod vertebrate's otocyst formation occurs by invagination, but zebra fish otic vesicle forms by cavitations rather than imagination.

In the present study, at the early stages of development of the inner ear ( $15 \mathrm{~mm}$ embryo stage), the endolymphatic duct appeared firstly from the latero-dorsal part. Then it enlarges to a sac .This sequence agrees with the results from the studies of (Bissonnette \& Fekete, 1996; Mansour et al., 1993 and Morsil et al., 1998). They explained that the sculpting of otic vesicle in to a complex membranous labyrinth and first structure that bulges out from the otocyst close to the closure point at $\mathrm{HH} 23$ chicken and E10 in mouse. Also (Bever \& Fekete, 2002), found that the endolymphatic duct is the first ear structures to form in amniotes but forms relatively late during larval development in Zebra fish. In the present study, the cochlear duct that is the auditory organ in the columba, is the following structure to be appeared in the developing otocyst from its ventral wall( $22 \mathrm{~mm}$ embryo stage). The columba cochlear duct is not coiled but, relatively straight or twisted. Torres et al. (1996) in their studies on the avian inner ear observed the same result and the chick cochlear duct is apparent in HH23. In his other studies on the mouse, Torres found that the mammalian cochlear duct is coiled and it is apparent in E10.75. The twisting of the cochlear duct is quite complex in the long ducts of owls (Schwartzkopff \&Winter, 1960 and Fischer et al., 1988). The basilar papilla and cochlear duct of the barn own Tyto alba is the longest so far described in birds, being over $11 \mathrm{~mm}$ in length in the unfixed state and in the fixed, dried state, it is roughly $9 \mathrm{~mm}$ long (Tilney \& Saunders, 1983; Tilney et al., 1987 and Gleich \& Manley 1988)

In the present study ( $36 \& 47 \mathrm{~mm}$ stages), the intermediate membranous labyrinth consists of two parts, dorsal vestibular (pars superior) and ventral auditory part (pars inferior). The vestibular part is similar among all vertebrates and consists of two connecting sacs (the utricle and the saccule) with their gravity sensing macula, and the semicircular canals, whose ampullary connections to the utricle contain rotation-sensing crista. .The auditory part (the cochlear duct) is the ventral part and is of an auditory function. The morphology of the ventral part of the ear is more specific to each class of vertebrate. Anniko (1983); Lewies et al. (1985) and Bever \&Fekete (2002) explained that utricle and semicircular ducts constitute the vestibular apparatus, the structure and function of which has been highly conserved in all vertebrates. They also explained that the auditory chambers have undergone extensive evolutionary modifications and that the saccule is a prominent auditory endorgan in fish but it serves a vestibular role in mammals and birds and the primary auditory endorgan in birds and mammals is the cochlea which has no known counter- part in fishes and amphibians.

(Baird, 1974; Propper et al., 1992) also explained that the vertebrate inner ear is a complex labyrinth containing multiple sensory organs. The pars superior (dorsal part of the ear) is similar among all vertebrates and consists of a central utricle, with its gravity sensing macula, and the semicircular canals, whose ampullary connections to the utricle contain rotation-sensing crista. The morphology of the pars inferior (ventral part of the ear) is more specific to each class of vertebrate, but it typically consists of saccular and lagenar pouches, whose maculae function in vestibu- lar roles, auditory roles, or both. Additional diverticula with sensory patches specialized for hearing is found in amphibians, reptiles, birds and mammals. Also Goldberg and Hudspeth, (2000) explained that the three vestibular canals and their associated cristae respond to angular acceleration, while the utricle and saccule with their respective macula respond to gravity and linear acceleration . The findings of (Fay \& Popper, 2002 and Cantos et al., 2004) found that mammalian and avian hearing system includes a cochlear duct, whereas Fish and amphibians lack cochlea and the saccule have developed into an auditory structure. They also explained that morphogenesis, the connection that eventually separates the saccule and the elongating cochlear duct begins to thin and the localized programmed cell death at the base of the cochlear duct is important for its outgrowth in the mouse and chick. This cluster of dying cells has not been described in the xenopeus and zebra fish which also lack the cochlear structure.

In the present work, the formation of the three semicircular ducts initiates from paired outpocketings of otic epithelium $(33 \mathrm{~mm}$ embryo stage) then the two epithelial layers on the opposing walls become thinner and approach each other to form a fusion plate. Afterwards, the epithelial cells of the fusion plate disappear via possible mechanism of involving either programmed cell death or epithelial cell retraction or both ( $47 \mathrm{~mm}$ embryo stage ).These results agreed with the studies of Sher, (1971) ; Martin \& Swanson, ( 1993 ) ; Bissonnette \& Fekete ,(1996) ; Fekete et al.(1997); Morsli et al.( 1998 ) ; cantos et al.( 2000 ) and Kobayashi, ( 2008) on the Gallus, fowl and mouse. They described the same steps of the formation of the ducts but in the process of removing the fusion plate cells mechanism, there was a difference. Martin and Swanson found that the fusion plate cells are thought to be recruited back into the duct epithelium in the mouse and other mammals. On the other hand, in Gallus, Fekete et al. found that the programmed cell death has been shown in removing the fusion plate cells.

In the present study, the sensory organs of the Columba inner ear of $47 \mathrm{~mm}$ embryo are divided to dorsal vestibular and ventral auditory organs. There is one auditory organ, the organ of corti or the basilar papillae inside the cochlear duct, and fife vestibular organs. The vestibular organs are the three crista ampullaris of the three semicircular canals, the macula saccule, the macula uticulus .These results are similar to that described by Swanson et al. (1990) in his study on the chick inner ear, there is one auditory sensory organ known as the basilar papilla, and a vestibular organs that include three crista ampullae and two maculae.

In the present study, the first sensory organ in columba, is the crista ampullais posterior of the posterior semicircular canal (in $36 \mathrm{~mm}$ embryo stage ) followed by the anterior crista of the anterior semicircular canal then macula uticulus, macula saccule and lateral crista and then basilar pabilla the crisa ampullais posterior ( in $47 \mathrm{~mm}$ embryo stage ).

Rubel, 1978; Wu \& Oh, 1996; Riley \& Phillips, 2003 and Barald \& Kelley, 2004 found that the avian inner ear consisting of eight sensory organs which in the early and intermediate stages do not show any definite development of hair and support cells in the early stages but all are dark staining cells. They also found that the anterior and the posterior crista are the first sensory organs to appear. (Fritzsch et al., 2002) explained that the number of the sensory organs involved in balance and auditory function varies across the vertebrates from thee in hag fish, six in mammals, eight in birds and frog to nine in some species of limbless amphbians. (Baird, 1974 \& Propper et al., 1992) also explained that the vertebrate inner ear is a complex labyrinth containing multiple sensory organs.

\section{Conclusions}

During the early development (10 $\mathrm{mm}$ stage), neuroepithelium of the ventral rhompencephalon evaginates laterally to form an ectoderm thickening, the otic placode. The latter invaginates forming the otocyst .The endolymphatic duct is the first appeared structure 
in $15 \mathrm{~mm}$ stage, followed by cochlear duct (in $22 \mathrm{~mm}$ stage) and finally the three semicircular ducts. The inner ear contains sensory organs; the macula of (utriclus, sacculus) and the crista ampullaris (of the three semicircular canals) and the basilar papillae of the cochlear duct .These sensory organs are not yet differentiatated to hair or supporting cells.

\section{Acknowledgement}

The authors would like to thank the head of Zoology Department, Faculty of Science, Benha University, for the help offered me through the preparation of this manuscript.

\section{References}

[1] Alsina B, Giraldez F and Pujades C (2009), Patterning and cell fate in ear development. Int. J. Dev. Biol 53, 1503-1513.

[2] Anniko M (1983), embryonic development of vestibular sense organs and their innervations. In: R. Romand, Editor, Development of $\mathrm{Au}-$ ditory and Vestibular Systems, Academic Press, New York, pp. 375423.

[3] Baird IL (1974), Anatomical features of the inner ear in sub mammalian vertebrates. In: Keidel WD, Neff WD, editors.Handbook of sensory physiology V/I: auditory system. Berlin, Springer-Verlag P, 159212.

[4] Baker C V and Bronner-Fraser M (2001), Vertebrate cranial placodes I. Embryonic induction. Dev. Bio 232, 1-61.

[5] Barald KF and Kelley MW (2004), from placode to polarization new tunes in inner ear development. Development 131, 4119-4130.

[6] Bell D, Streit A, Gorospe I, Varela-Nieto I, Alsina, B and Giraldez,F (2008),Spatial and temporal segregation of auditory and vestibular neurons in the otic placode. Biol.322, 109-120.

[7] Bermingham N A, Hassan B A ,Price S, Vollrath M A ,Ben-Arie N, Eatock R A, Bellen H J, Lysakowski, A and Zoghbi H Y (1999), Math1: an essential gene for the generation of inner ear hair cells. Science 284, 1837-1841.

[8] Bermingham-McDonough O. and Rubel E W (2003), Hair cell regeneration: winging our way towards a sound future. Curr Opin Neurobiol13 (1), 119-126.

[9] Bever M.M. and Fekete D M (2002). Atlas of the developing inner ear in zebra fish. Dev. Dyn. 223 pp, 536-543.

[10]Bissonnette J P and Fekete D M (1996), Standard atlas of the gross anatomy of the developing inner ear of the chicken. J Comp Neural 174, 1-11.

[11]Cantos R, Cole L K, Acampora, D, Simeone A and Wu D K (2004), Patterning of the mammalian cochlea. Proc Natl Acad Sci U S A. 97, 11707-11713.

[12]Chen P.; Johnson, J. E.; Zoghbi, H. Y. and Segil, N. (2002): The role of Math1 in inner ear development: Uncoupling the establishment of the sensory primordium from hair cell fate determination. Development 129, 2495-2505

[13]Cohen G M and Fermin C D (1978): The development of hair cells in the embryonic chick's basilar papilla. Acta Otolaryngol 86,342-358.

[14]Corwin J T and Cotanche D A (1988): Regeneration of sensory hair cells after acoustic trauma. Science. 240(4860), 1772-1779.

[15]Cotanche D A (1987), Regeneration of hair cell stereociliary bundles in the chick cochlea following severe acoustic trauma. Hear Res.30 (2-3), 181-195.

[16]Couloigner V, Teixeira M.and Sterkers O, Rask-Andersen, H. and Ferrary, E, (2004): The Endolymphatic Sac: It's Roles in the Inner Ear Med Sci (Paris) 20, 304-310.

[17]Cruz R M, Lambert P R and Rubel E W (1987), Light microscopic evidence of hair cell regeneration after gentamicin toxicity in chick cochlea. Arch Otolaryngol Head Neck Surg.113 (10), 1058-1062.

[18]Dallos P (1988), cochlear Neurobiology = revolutionary developments. A. S. H. A. 30(6-7), 50-60.

[19]Donaldso J A Duckert L G. Lampert P M. and Rubel E W (1992), Anatomy of the temporal bone. Springer Hand book of Auditory Research. Springer-Verlag, New York.

[20]Dooling R J ,Fay R R and Popper A N ( 2000), Springer Handbook of Auditory Research, vol .13, Comparative Hearing in Reptiles and Birds. New York, Springe.

[21]Dooling R J and Saunders, J C (1973): Hearing in the parakeet (Melopsittacus undulates): Absolute thresholds, critical ratios, frequency difference limens, and vocalizations. J. Comp Physiol Psycho $88,1-20$
[22]Eddison M., Roux,I and Lewis, J (2002): Notch signaling in the development of the inner ear. Lessons from Drosophila. Proc. Natl. Acad. Sci. USA 97, 11692-11699.

[23]Fay R R. and Popper A N (2002), Comparative hearing: fish and amphibians. In: Fay RR, Popper AN, editors. Springer Hand book of Auditory Research. Springer-Verlag, New York.

[24]Fekete D M (1996), Cell fate specification in the inner ear. Curr. Opin Neurobiol 6, 533-541.

[25]Fekete DM (1999), Development of the vertebrate ear: insights from knockouts and mutants. Trends Neurosci 22,263-268.

[26]Fekete D M., Homburger S A, Waring M T, Riedl A E and Garcia L F (1997), Involvement of programmed cell death in morphogenesis of the vertebrate inner ear. Development. 124, 2451-2461.

[27]Fekete D M, Muthukuma S, Fischer FP, Koppl C and Manley GA, (1988), The basilar papilla of the barn owl Tyto alba: A quantitative morphological SEM analysis. Hearing Res 34, 87-101.

[28]Fritzsch B, Barald K.F and Lomax M.I (1997), early embryology of the vertebrate ear. In: Popper AN, Rubel E, Fay RR, editors. Handbook of the auditory system. New York Springer-Verlag. P, 80-145.

[29]Fritzsch B, Beisel K W and Bermingham N A (2000), Developmental evolutionary biology of the vertebrate ear: conserving mechanoelectric transduction and developmental pathways in diverging morphologies. NeuroReport 11, R35-R44.

[30]Fritzsch B, Beisel K W and Hansen, L A (2006), The molecular basis of neurosensory cell formation in ear development: a blue print for hair cell and sensory neuron regeneration? BioEssays 28 1181-1193.

[31] Fritzsch B , Beisel,K W, Jones K Farinas,I.A,Maklad,A,lee,J and Reichardt L F (2002), Development and evolution of inner ear sensory epithelia and their innervations . Neurobiol. 53, pp.143-156.

[32] Gleich O, Manley GA (1988): Quantitative morphological analysis of the sensory epithelium of the starling and pigeon basilar papilla. Hearing Res34, 69-86.

[33] Goldberg M E and Hudspeth A J, (2000), the vestibular system. In Principles of Neural Science (ed. E. R. Kandel, J. H. Schwartz and T. M. Jessell), pp. 801-815. New York, McGraw-Hill.

[34]Haddon C and Lewis J (1996), Early ear development in the embryo of the zebra fish, Danio rerio. J.Comp. Neurol. 36, pp.113-128.

[35] Jones T A, Jones S M and Paggett K C (2006), Emergence of hearing in the chicken embryo. Neurophysiol 96,128-141.

[36] Knowlton V Y (1967) Correlation of the development of membranous and bony labyrinth acoustics ganglia, nerves, and brain centers of the chick embryos. J. Morphol. 121,179-208.

[37]Kobayashi Y, Nakamura H and Funahashi J. (2008), Epithelialmesenchymal transition as a possible mechanism of semicircular canal morphogenesis in chick inner ear. Tohoku J Exp Med. 215, 207-21

[38]Lewis J (1991), Rules for the production of sensory cells. In Regeneration of Vertebrate Sensory Receptor Cells (ed. G. R. Bock and J. Whelan), pp. 25-53

[39]Lewis E R, Leverenz, EL and Bialek, WS (1985), The Vertebrate Inner Ear, CRC Press, Boca Raton, FL

[40]Manley G A (1990), Peripheral Hearing Mechanisms in Reptiles and Birds. New York: S pringer-Verlag.

[41]Mansour S L, Goddard J M, Capecchi, M R (1993), Micehomozygous for a targeted disruption of the proto-oncogene int-2 has developmental defects in the tail and inner ear. Development 117, 13-28.

[42] Martin P and Swanson G J (1993), Descriptive and experimental analysis of the epithelial remodel that control semicircular canal formation in the developing mouse inner ear. Dev Biol. 159, 549-558

[43]Morsli H , Choo D, Ryan A, Johnson R and Wu D K (1998) ,Development of the mouse inner ear and origin of its sensory organs. J Neurosci. 18,3327-3335.

[44]Propper AN, Platt C and Edds P L (1992), Evolution of the vertebrate inner ear: an overview of ideas. In: Webster DB, Fay R.R., Popper A.N.,editors. The evolutionary biology of hearing. New York: Springer-Verlag. P, 49-57

[45]Riley, B. and Phillips, B.T. (2003): Ringing in the new ear: resolution of cell interactions in otic development. Dev Biol 261:289-312.

[46]Romanoff an L (1996) the organ of special sense. In: The avian embryo structure and function, pp 365-381. New York: MacMillan.

[47]Rubel E W (1978), Ontogeny of auditory structure and function in vertebrate auditory system. In: Jacobsen M, ed. Handbook of Sensory Physiology, vol IX: Development of Sensory Systems. New York: Springer-Verlag. p 135-237.

[48]Ryals B M. and Rubel E W (1988), Hair cell regeneration after acoustic trauma in adult Coturnix quail. Science.240 (4860), 1774-1776

[49] Satoh T and Fekete D M. (2005), Clonal analysis of the relationships between mechanosensory cells and the neurons that innervate them in the chicken ear Development 132, 1687- 1697. 
[50]Saunders J C, Coles R B and Gates G R (1973), the development of auditory evoked responses in the cochlea and cochlear nuclei of the chick. Brain Res 63, 59-74.

[51]Saunders J C. and Henry W J (1988), the peripheral auditory system of birds: Structural and functional contributions to auditory perception. In: Dooling, R.J., Hulse. W.M., eds. Contributions to Auditory Perception in Animals. Collingswood NJ: Earlbaum..P.31-62.

[52]Saunders J C. and HenryW J (1988), the peripheral auditory system of birds: Structural and functional contributions to auditory perception. In: Dooling, R.J., Hulse. W.M., eds. Contributions to Auditory Perception in Animals. Collingswood NJ: Earlbaum.p.31-62.

[53]Schlosser G (2010), Making senses development of vertebrate cranial placodes.Int. Rev. Cell Mol. Biol. 283, 129-234

[54]Schwartzkopff J and Winter P (1960), Zur Anatomies der VogelCochlea under naturlichen Bedingungen. Biologists' Zentralblatt 79,607-625.

[55]Sher an E (1971), the embryonic and postnatal development of the inner ear of the mouse.Acta Otolaryngol. (Suppl.) 285, 1-77.

[56]Smolders J W (1999, Functional recovery in the avian ear after hair cell regeneration. Audiol Neurootol. 4(6), 286-300.

[57]Swanson G J, Howard M. and Lewis J (1990) Epithelial Autonomy in the development of the inner ear of a bird embryo. Dev Biol 137,243257.

[58]Tilney LG and Saunders JC (1983): Actin filaments, stereocilia, and hair cells of the bird cochlea. I. Length, number, width, and distribution of stereocilia of each hair cell are related to the position of the hair cell on the cochlea. J Cell Biol 96:807-821.

[59]Tilney M S, Tilney L G.and DeRosier D J (1987), the distain of hair cell bundle lengths and orientations suggests an unexpected pattern of hair cell stimulation in the chick colea. Hearing Res 25,141-151.

[60]Torres and Giraldez F (1998), The development of the Vertebrate inner ear, MechDev .71, 5-21

[61] Tucker A S, Watson R P, Lettice L A,Yamada G and Hill R E (2004), Bapx1 regulates patterning in the middle ear: Altered regulatory role in the transition from proximal jaw during vertebrate evolution,Develop.131 (6), 12351245

[62]Von Bartheld C S, Patterson S L, Heuer J G, Wheeler E F, Bothwell M. and Rubel E W (1991), Expression of Nerve growth factor (NGF) receptors in the developing inner Ear of chick and rat. Development $113.455-470$.

[63]Wu D K and Oh S H (1996), Sensory organ generation in the Chick inner ear. J Neurosci .16:6454-6462

[64]Zheng J L and Gao W Q. (2000), over expression of Math1 Induces robust production of extra hair cells in postnatal rat Inner ears. Nat. Neurosci. 3, 580-586. 